\title{
La jurisdicción especial para la paz: un modelo de justicia transicional en Colombia
}

Special jurisdiction for peace:

Colombia's model of transitional justice

María Camila Correa Flórez Universidad del Rosario, Colombia $\mid$ mariaca.correa@urosario.edu.co

Andrés Felipe Martín Parada Universidad del Rosario, Colombia $\mid \underline{\text { andresf.martin@urosario.edu.co }}$

Recibido: 1/10/2020

Aceptado: $\quad 25 / 11 / 2020$

Resumen Este texto pretende exponer el funcionamiento de la Jurisdicción Especial para la Paz como un modelo de justicia transicional. Para ello se explican los procesos que se llevan a cabo al interior de la Jurisdicción Especial, que son ejemplificados a través de casos específicos que muestran los retos que tiene esta institución como parte del modelo actual de Justicia Transicional en Colombia.

Palabras clave: Justicia Transicional, Jurisdicción Especial para la Paz, Colombia, Derechos de las víctimas.

Abstract: This text aims to explain the operation of the Special Jurisdiction for Peace as a model of transitional justice whose central axis is the rights of the victims. To do this, the processes that are carried out within the jurisdiction are explained and exemplified through specific cases that show the challenges that this transitional justice model has.

Keywords: Transitional Justice, Special Jurisdiction for Peace, Colombia, Victim's rights.

Cómo citar este artículo: Correa Flórez, M. C. y Martin Parada, A. F. (2020). La jurisdicción especial para la paz: un modelo de justicia transicional en Colombia. Revista Electrónica de Derecho Internacional Contemporáneo, 3 (3), 30 - 50. https://doi.org/10.24215/2618303Xe002 


\section{Introducción}

A lo largo de las siguientes páginas se hará un recorrido por el funcionamiento de la Jurisdicción Especial para la Paz (JEP) de Colombia, por medio de las normas que la crearon y de algunas de sus resoluciones más destacadas. El objetivo de este análisis es acercar al lector al sistema actual de Justicia Transicional que opera en Colombia luego de la firma del Acuerdo de Paz suscrito entre el Gobierno Nacional y las Fuerzas Armadas Revolucionarias de Colombia (FARC-EP). En primer lugar, se parte de una revisión bibliográfica de importantes autores en materia de justicia transicional, luego de ello se hace una breve exposición de los procedimientos ante la JEP con la finalidad de contextualizar al lector. Y, finalmente, se exponen distintos casos que han tenido lugar ente la JEP que, no solo ejemplifican su funcionamienmto, sino que también ponen de manifiesto los retos que asume la JEP en su labor de administración de justicia. Con ello se evidencia la relevancia de este órgano jurisdiccional como modelo de justicia transicional.

Existen diversas concepciones y formas de aproximarse al concepto de Justicia Transicional. Sin embargo, parece haber un acuerdo en que se trata de una manifestación de la justicia que se aplica en períodos de "transformaciones políticas radicales" (Teitel, 2000, p. 4). Estas trasformaciones políticas radicales pueden darse en periodos posteriores a conflictos armados o períodos posteriores a regímenes políticos dictatoriales, donde, como es evidente, se dieron situaciones de violencia masiva y violaciones a derechos humanos de forma generalizada.

Se trata entonces de un conjunto de mecanismos jurídicos de carácter retributivo, restaurativo y sancionador, a través de los cuales se busca restablecer la convivencia y la estabilidad política y social, a través de "la confrontación con los hechos pasados" (Knust, 2018, p. 146). Este conjunto de mecanismos jurídicos incluye procesos penales de responsabilidad individual, que suelen focalizarse en las máximas posiciones de responsabilidad, las reparaciones de las víctimas, el reconocimiento de los perpetradores, el ofrecimiento de disculpas tanto a las víctimas como a la sociedad y la posibilidad de los perpetradores de reconocer su participación en actos violentos. Todo ello con la finalidad última de alcanzar una paz sustentable y duradera y la reconciliación de la sociedad colombiana.

Como bien lo evidencia Knust, el concepto de Justicia Transicional está en constante desarrollo "vinculado a las circunstancias de tiempo y lugar" (Knust, 2018, p. 147). De allí que no se pueda decir que todos los modelos de Justicia Transicional son idénticos y responden a necesidades iguales ${ }^{1}$ (De Greiff, 2011, p. 10). Así, es posible establecer que el actual modelo de Justicia Transicional colombiano no puede encuadrar en un tipo específico de Justicia Transicional, sino que, por el contexto histórico y social del país, se crearon una serie de medidas de carácter compensatorio, retributivo, restaurativo y transformador, cuyo propósito es la restauración de los derechos de las víctimas y la recomposición del tejido social quebrantado por el conflicto armado. Se trata entonces de un sistema de "carácter dinámico" que "tiene unas especificidades que les permiten tener características de uno o varios tipos, así como comenzar escogiendo una vía transicional y terminar optando por otra" (Uprimny, 2006, p. 17).

La suscripción del "Acuerdo final para la terminación del conflicto armado y la construcción de una Paz Estable y Duradera" en diciembre de 2016, producto del proceso de negociaciones en La Habana, Cuba, el cual culminó con celebración del Acuerdo Final entre el Gobierno de Colombia y las Guerrillas las FARC EP. Sin embargo, este no ha sido el único intento de paz en Colombia. Antes del año 2016, Colombia había celebrado diversas negociaciones con distintos actores involucrados en el conflicto armado (Álvaro Villarraga- Sarmiento, 2016).

\footnotetext{
${ }^{1}$ Pablo De Greiff sostiene que las medidas de justicia transicional deben responder ciertamente al contexto en que están deben darse con el fin de "servir las necesidades recurrentes en el nuevo contexto de aplicación" de esta justicia.
} 
Desde el Gobierno militar de Gustavo Rojas Pinilla, en los años comprendidos entre 1953 a 1957, lapso en el cual se dieron "dos procesos de paz con las guerrillas liberales con el fin de obtener su desmovilización y eliminar la violencia que se había desatado con la muerte del líder del Partido Liberal Jorge Eliecer Gaitán el 9 de abril de 1948"(Benavides Vanegas \& Borda Guzmán, 2019, p. 8), pasando por los procesos de paz con distintos grupos guerrilleros en los años 80, hasta llegar a los Gobiernos de Virgilio Barco (1986 - 1990) y Cesar Gaviria (1990-1994), se han forjado numerosos intentos para terminar el conflicto armado de más de cinco décadas. Para algunos autores, como Eduardo Pizarro (2017), Farid Benavides (2019) o Sandra Borda (2019), los procesos que se dieron en la década de los 90, resultaron ser parcialmente exitosos, pues se desmovilizaron grupos guerrilleros como el Movimiento 19 de abril de 1970 (M - 19), así como también una facción del Ejército de Liberación Nacional (ELN), el Partido Revolucionario de los Trabajadores (PRT), el Movimiento Armado Manuel Quintín Lame (MAMQL) y una facción del Ejército Popular de Liberación (EPL) (Benavides Vanegas \& Borda Guzmán, 2019, p. 9).

No obstante, todo esto fue insuficiente para erradicar la ola de violencia que azotó a Colombia en los años 90, pues pese los esfuerzos de los gobiernos de turno por acabar con el conflicto, aún no se habían podido llegar a acuerdos con las FARC - EP. De los 1000 municipios (aproximadamente) que conformaban Colombia en 1998, al menos 419 estaban permeados por la violencia y eran blanco de ataques armados por parte de las FARC - EP (Ávila, 2019, p. 78). De igual forma, entre 1997 y 1999 se dio un crecimiento de la actividad armada de esta guerrilla en al menos 40 municipios del país y dado que esta guerrilla no tenía ni la intención, ni la capacidad de influenciar en la política colombiana, lo que buscaban era destruir al Estado (Ávila, 2019, p.86), por lo que los ataques contra el sector público en los años 1997 y 1998, fueron creciendo de manera exponencial; para este periodo de tiempo se produjeron al menos 242 homicidios, 738 secuestros y más de 220 atentados en contra de funcionarios públicos en distintos departamentos de Colombia, lo cual evidenciaba el poder armado que tenía esa guerrilla durante estos años (López, 2010, p. 33).

El gobierno presidido por el entonces presidente Álvaro Uribe Vélez (2002 - 2010), tampoco fue ajeno a la negociación de la paz con grupos armados. Durante este período se produjo la desmovilización de varios combatientes pertenecientes a grupos paramilitares en el marco de la denominada "Ley de Jsuticia y Paz (Ley 975 de 2005)". Este proceso resultó ser exitoso en cuanto a la desmovilización de los combatientes (Valencia, 2008), pero no frente al juzgamiento, la sanción de líderes paramilitares y menos frente a la garantía de derechos de las víctimas. El Centro Nacional de Memoria Histórica afirma que en Colombia la Ley 975 de 2005 (Ley de "Justicia y Paz") no creó un escenario idóneo en el que las víctimas fueran las protagonistas del proceso, ya que, pese "a su centralidad en la definición de los propósitos, (...) el proceso judicial [de esta ley] no incentivaba la expresión de sus traumas colectivos y se limitaba a reclamar por sus parientes asesinados. [Era] como si la necesaria individualización de la pena en el proceso judicial implicara la individualización del objeto de reclamo que hace la víctima" (Barbosa Delgado, 2018, p. 26).

Sumado a lo anterior, "la presencia paramilitar no disminuyó en muchas zonas, surgieron nuevos grupos armados, las víctimas no fueron totalmente reparadas y los derechos a la verdad y la garantía de no repetición no parecieron realizarse con posterioridad a los acuerdos de paz del Gobierno con los grupos paramilitares" (Benavides Vanegas \& Borda Guzmán, 2019, p. 9).

Ahora bien, de los procesos de paz anteriormente mencionados surgieron importantes modelos en materia de Justicia Transicional que permiten entender el modelo actual desarrollado a través de las discusiones de La Habana y el marco jurídico que lo integró a la legislación colombiana. Así por ejemplo, uno de los resultados en materia jurídica del proceso realizado entre el gobierno de Álvaro Uribe y los grupos paramilitares, fue la Ley 975 de 2005 ("Ley de Justicia y Paz") que introdujo, por primera vez, el componente de los derechos de las víctimas y, según Abuchaibe, este fue el primer instrumento legal que introdujo conceptos de Justicia Transicional dentro del ordenamiento jurídico colombiano (Abuchaibe, 2017, p. 132). En segundo lugar, en el marco de este proceso, se promulgó la Ley 1424 de 2010, referente a la reintegración de los desmovilizados de las Autodefensas Unidas de Colombia y, en tercer lugar, la Ley 1448 de 2011, que regula el proceso de 
restitución de tierras. La restitución de tierras fue, más tarde, un eje principal en las discusiones de La Habana (Calafat, 2016, p. 99).

Estos antecedentes fueron claves para fundamentar la línea sobre la cual se cimentaría el "Acuerdo de paz para la terminación del conflicto armado y una paz estable duradera". En el año 2010, y luego de algunos contactos que tuvo el gobierno Uribe con las FARC - EP, se comenzaron, bajo el gobierno Santos, a tejer los diálogos de La Habana que culminaron con la suscripción del mencionado acuerdo de paz. Es de resaltar, que las negociaciones se dieron alrededor de cinco puntos específicos en el marco de una agenda clara para las negociaciones entre las dos partes: "1. Una reforma integral del campo colombiano. 2. Apertura democrática para construir la paz y participación política. 3. Acuerdo sobre el cese el fuego y de hostilidades y dejación de las armas; así como un acuerdo sobre las garantías de seguridad. 4. Solución al problema de las drogas ilícitas. 5. Acuerdo sobre las víctimas del conflicto"(Benavides Vanegas \& Borda Guzmán, 2019, p. 14), dentro del que se estableció la creación del Sistema Integral de Verdad, Justicia, Reparación y no Repetición (SIVJRNR).

Este último artículo fue formalmente introducido al ordenamiento colombiano por medio del Acto Legislativo 01 de 2017, que establece la creación del SIVJRNR compuesto por dos instituciones extrajudiciales: "La Comisión para el Esclarecimiento de la verdad, la convivencia y la no repetición" y "La Unidad de Búsqueda de personas dadas por desaparecidas en el contexto y debido al conflicto armado". A su vez, se dispuso la creación de una institución de carácter judicial denominado: Jurisdicción Especial para la Paz (JEP) ${ }^{2}$.

\section{La Jurisdicción Especial para la Paz: objetivos, estructura y funcionamiento}

\section{f. Objetivos de la Jurisdicción Especial para la Paz (JEP)}

El artículo transitorio 05 del Acto Legislativo 01 de 2017 dispuso que la JEP sería el órgano que administraría justicia de manera transitoria, autónoma y exclusiva frente a conductas relacionadas con ocasión al conflicto armado y que contaría con un régimen legal propio, dotada además de autonomía administrativa, presupuestal y técnica ${ }^{3}$. Asimismo, este artículo consagra que los objetivos de esta jurisdicción son:

“(...) satisfacer el derecho de las víctimas a la justicia; ofrecer verdad a la sociedad colombiana; proteger los derechos de las víctimas; contribuir al logro de una paz estable y duradera; y adoptar decisiones que otorguen plena seguridad jurídica a quienes participaron de manera directa o indirecta en el conflicto armado interno mediante la comisión de las mencionadas conductas. Respecto de los combatientes de los grupos armados al margen de la ley, el componente de justicia del Sistema solo se aplicará a quienes suscriban un acuerdo final de paz con el Gobierno Nacional."

De este modo, se debe resaltar que la JEP, como un modelo de Justicia Transicional, tiene dos objetivos. El primero, hace referencia a "garantizar los presupuestos necesarios para asegurar la reconciliación y el establecimiento de una paz estable y duradera" 4 en otras palabras, poner fin a la guerra y "alcanzar la paz para todos los combatientes, sobre la base de la reconciliación de todos los actores, para garantizar la no repetición" (Ferrajoli, 2015). Dijo objetivo, no puede ser alcanzado a través de la denominada "justicia ordinaria" porque su carácter limitante en relación a los objetivos mencionados. En primer lugar, porque "la violencia

\footnotetext{
${ }^{2}$ Acto Legislativo 01 de 04 de abril de 2017. Artículos transitorios, 2, 3, y 4.

${ }^{3}$ El tenor literal del articulo 5 del Acto Legislativo 01 de 2017 consagra: "La Jurisdicción Especial para la Paz estará sujeta a un régimen legal propio, con autonomía administrativa, presupuestal y técnica; administrará justicia de manera transitoria y autónoma y conocerá de manera preferente sobre todas las demás jurisdicciones y de forma exclusiva de las conductas cometidas con anterioridad al 10 de diciembre de 2016, por causa, con ocasión o en relación directa o indirecta con el conflicto armado, por quienes participaron en el mismo, en especial respecto a conductas consideradas graves infracciones al Derecho Internacional Humanitario o graves violaciones de los Derechos Humanos".
}

${ }^{4}$ Ley 1922 de 2018, literal a, artículo 1. 
en el estado de guerra no puede ser valorada ni calificada con el criterio penal que regularmente aplica" y, en segundo lugar, porque "para alcanzar la paz no se puede tratar a los combatientes como criminales ordinarios, salvo que se hayan presentado crímenes de guerra o crímenes de lesa humanidad" (Castro Cuenca, 2020, p. 2).

Respecto del segundo objetivo de la JEP, el "tratar con el pasado", eso incluiría las conductas delictivas que tuvieron lugar en el marco del conflicto como parte de la competencia de la JEP. En este punto, el Derecho penal y el Derecho procesal penal cobran importancia dentro del marco de la Justicia Transicional. Estos no solo van a girar en torno al derecho a la justicia de las víctimas, "sino que los juicios en la transición trazan la línea entre el anterior y el nuevo régimen y condenan la violencia del pasado, (...) lo cual resulta fundamental para la consolidación de una nueva democracia y la construcción de un nuevo orden legal" (Castro Cuenca, 2020, p. 3).

En conclusión, la JEP como órgano de Justicia Transicional está llamada no sólo a contribuir al proceso de paz y la reconciliación, sino que además deberá juzgar los actos cometidos de forma retroactiva. Es importante mencionar que, el carácter excepcional de la Jurisdicción Transicional, está limitada en el tiempo pues su competencia temporal se limita a conductas cometidas antes del 1 de diciembre de 2016. De igual manera, según el artículo 15 transitorio del Acto Legislativo 1/2017, la JEP tiene un mandato de funcionamiento de diez años, prorrogables por cinco años más. Así las cosas, por sus características de creación y duración determinada, la JEP se constituye como un organismo que imparte Justicia Transicional.

\section{g. Estructura y funcionamiento de la JEP}

Respecto a la estructura de la Jurisdicción, en el artículo transitorio 7 del mencionado Acto Legislativo se estableció que la JEP estará compuesta por la Sala de Reconocimiento de Verdad, de Responsabilidad y de Determinación de los Hechos y Conductas, la Sala de Definición de Situaciones jurídicas; la Unidad de Investigación y Acusación, la Secretaria ejecutiva y por el Tribunal para la Paz, el cual será el órgano de cierre de esta jurisdicción, que a su vez, estará conformado por "dos secciones de primera instancia, una Sección de Revisión de Sentencias, una Sección de Apelación y la Sección de Estabilidad y Eficacia"s.

En el siguiente gráfico, se muestra la organización antes enunciada:

\footnotetext{
${ }^{5}$ El artículo 7 del Acto Legislativo 01 de 2017 establece en su tenor literal lo siguiente: "La Jurisdicción estará compuesta por la Sala de Reconocimiento de Verdad, de Responsabilidad y de Determinación de los Hechos y Conductas, la Sala de Definición de las situaciones jurídicas, salas que desarrollarán su trabajo conforme a criterios de priorización elaborados a partir de la gravedad y representatividad de los delitos y del grado de responsabilidad en los mismos; la Sala de Amnistía o Indulto; el Tribunal para la Paz; la Unidad de Investigación y Acusación, y la Secretaría Ejecutiva. La Jurisdicción contará además con un Presidente. El Tribunal para la Paz es el órgano de cierre y la máxima instancia de la Jurisdicción Especial para la Paz. Estará conformado por dos secciones de primera instancia, una Sección de Revisión de Sentencias, una Sección de Apelación y la Sección de Estabilidad y Eficacia”.
} 


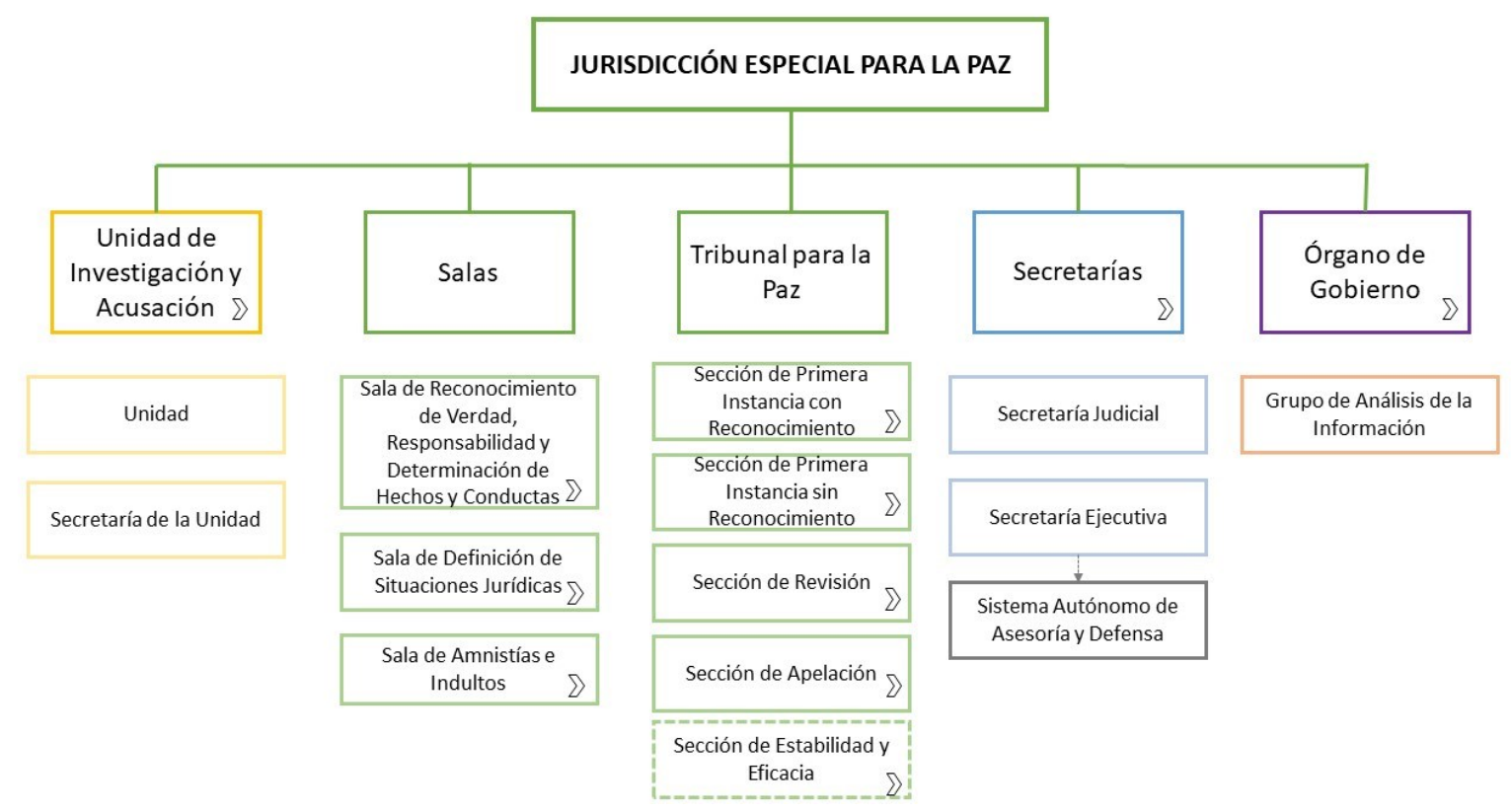

Gráfica 1. Fuente: ObservaJEP en “¿Cómo funciona la JEP? Recuperado de: http://observajep.com/index.php?xid=8\&xstr=abc-del-sivjrnr

De igual manera, el propio Acto Legislativo enumera los factores de competencia personal, material y temporal. Respecto a la competencia personal, solo se pueden someter a la JEP aquellas personas que participaron en conductas con ocasión o en relación directa o indirecta con el conflicto armado. El artículo 5 del Acto Legislativo en mención, agrega que "respecto de los combatientes de los grupos armados al margen de la ley, el componente de justicia del Sistema solo se aplicará a quienes suscriban un acuerdo final de paz con el Gobierno Nacional". Esto quiere decir que la JEP solo tiene competencia sobre aquellas personas que pertenecieron a las FARC-EP, toda vez que este grupo es el único que ha suscrito un acuerdo de paz con el Gobierno Nacional.

Con respecto a la competencia material y temporal, el artículo 5 del Acto Legislativo 01 de 2017 establece, por un lado, que la JEP solo podrá conocer de conductas relacionadas de manera directa o indirecta con el conflicto armado de manera preferente sobre otras jurisdicciones y, por otro, que esas conductas que conocerá solo pueden ser aquellas cometidas antes del 1 de diciembre de 2016. Por ello, las conductas por fuera de ese marco temporal son competencia de la jurisdicción ordinaria.

Por otra parte, esa competencia preferente o prevalente que ostenta la JEP, hace referencia a que la JEP, desde su entrada en funcionamiento, tiene prioridad a la hora de conocer de situaciones que cumplan los factores arriba enumerados, frente a la Justicia Ordinaria, como lo establece el artículo 6 transitorio del Acto Legislativo 01 de 2017:

"El componente de justicia del SIVJRNR, conforme a lo establecido en el Acuerdo Final, prevalecerá sobre las actuaciones penales, disciplinarias o administrativas por conductas cometidas con ocasión, por causa o en relación directa o indirecta con el conflicto armado, al absorber la competencia exclusiva sobre dichas conductas."

Sin perjuicio de esto, la Justicia Ordinaria podrá mantener su derecho de jurisdicción respecto de determinados casos. Así lo ha reiterado la Sección de Apelación de esta Jurisdicción, al afirmar que:

"Es importante dejar sentado que los órganos judiciales que hacen parte del sistema penal ordinario tienen la competencia - la cual se mantiene - para resolver sobre las solicitudes de beneficios emanadas de las disposiciones contenidas en la Ley 1820 de 2016, aten- 
diendo para ello a los diferentes factores competenciales. Empero, con la entrada en funcionamiento pleno de los órganos que administran justicia dentro de la JEP, esto es, la Sala de Reconocimiento de Verdad, de Responsabilidad y de Determinación de los Hechos y Conductas, la Sala de Definición de las Situaciones Jurídicas y la Sala de Amnistía o Indulto, así como el Tribunal para la Paz, la competencia para atender estos asuntos se debe analizar de manera tal que se atienda tanto el alcance del carácter preferente de la JEP, como los postulados que se derivan del debido proceso." (Jurisdicción Especial para la Paz, Sección de Apelación, Auto TPSA- 001 de 2018 de 20 de abril de 2018, párrafo 26)

Así las cosas, la JEP mantiene una competencia prevalente para conocer de los casos que tuvieron lugar antes del 1 de diciembre de 2016, en los que estén involucrados actores del conflicto armado, y que además hayan sido cometidas por causa, con ocasión o en relación directa o indirecta con el conflicto armado ${ }^{6}$. Es importante aclarar que la expresión "actores del conflicto" debe entenderse en sentido amplio, toda vez que la JEP es competente para conocer de actuaciones cometidas por miembros de la fuerza pública, ex miembros de las FARC-EP $^{7}$ y colaboradores ${ }^{8}$ de esta organización y aquellos terceros que se sometan voluntariamente ${ }^{9}$.

Como se mencionó anteriormente, la JEP está compuesta por tres Salas de Justicia y por el Tribunal para la Paz. Cada una de estas Salas y Secciones tiene funciones determinadas que se deben cumplir siguiendo un procedimiento específico ${ }^{10}$. El Acto Legislativo 1 de 2017, en su artículo 12 transitorio, facultó a los Magistrados y a las Magistradas de la JEP para que una vez elegidos y posesionados participaran en la creación de normas de procedimiento de esta jurisdicción que después de largas jornadas de trabajo, fueron consignadas en la Ley 1922 de 2018.

Según lo establecido en el Acuerdo, la Sala de Reconocimiento de Verdad, de Responsabilidad y de Determinación de los Hechos y Conductas (Sala de RVRDHC) recibe los informes presentados por distintas instituciones del Estado y las organizaciones de víctimas, relativos a conductas cometidas con ocasión del conflicto armado. Una vez se establece que los hechos y conductas atribuidas a las distintas personas son competencia del Sistema de Justicia Transicional por haber sido cometidos en relación directa o indirecta con el conflicto armado interno o con ocasión de este, los informes se agrupan por presuntos autores o condenados y/o por conductas semejantes, sin que esto implique realizar una clasificación jurídica frente a la conduta cometida. Una vez realizada la agrupación en $\operatorname{casos}^{11}$, la Sala de RVRDHC, es la encargada de recibir las declaraciones de reconocimiento de

\footnotetext{
${ }^{6}$ Acto legislativo 01 de 2017, artículo 5 .

${ }^{7}$ Corte Constitucional. Sentencia C674/2017. "De igual modo, en la medida en que el esquema institucional introducido en el Acto Legislativo 01 de 2017 constituye un componente esencial del proceso transicional, resulta claro para la Corte que el mismo, sin afectar el principio de juez natural, es aplicable a todos los combatientes, con el objeto de garantizar el tratamiento simétrico a todos los actores del conflicto que se encuentran en posiciones jurídicas equivalentes. Por ello, que la Jurisdicción Especial para la Paz tenga competencia para investigar, juzgar y sancionar los delitos cometidos en el marco del conflicto por los miembros de la fuerza pública, tal como se establece en el artículo 21 del Acto Legislativo 01 de 2017, no comporta una anulación de la garantía del juez natural, en tanto el traslado competencial se realiza en el marco de un diseño que ofrece garantías simétricas y equivalentes a las que se contemplan para los grupos alzados en armas, sin que se advierta el propósito de disminuir las garantías orgánicas, procesales y sustantivas o de hacer más gravosa la situación de quienes se someten al sistema institucional de transición.

${ }^{8} \mathrm{Al}$ respecto, ver el artículo 22, numeral 1 de la Ley 1820 de 2016, que establece el factor de competencia personal de la Sala de Amnistía o Indulto.

${ }^{9}$ Artículo 16 transitorio del Acto Legislativo 1/2017. Es importante aclarar que "los agentes del Estado que no hacen parte de la fuerza pública se encuentran sometidos al mismo régimen de los terceros civiles previstos en el inciso 1 . del artículo transitorio 16". Corte Constitucional. Sentencia C674/2017.

${ }^{10}$ Por motivos de espacio, en este apartado se hará una referencia general a las funciones principales de cada Sala y Sección. De igual manera, se hará énfasis en los procedimientos regulados en la Ley 1922 de 2018.

${ }^{11}$ Actualmente, con base en los informes remitidos y expedientes remitidos, la Sala de Reconocimiento ha abierto siete casos, a saber: Caso 001:Retención ilegal de personas por parte de las FARC - EP; Caso 002: Situación municipios de Ricaurte, Tumaco y Barbacoas
} 
verdad y de responsabilidad, tanto individuales como colectivas. Así mismo, una vez cerrado el caso, la Sala debe "presentar resoluciones de conclusiones ante el Tribunal de conformidad con el listado de sanciones que corresponden a las respectivas conductas reconocidas. Así como presentar en una sola resolución y a la mayor brevedad las conclusiones que sobre una misma persona obren en la Sala por las diversas conductas de las que se tenga conocimiento" (Gobierno de Colombia FARC EP, 2016, pp. 154-156).

Acorde al artículo 27 A de la Ley 1922 de 2018, la Sala de RVRDHC debe recibir las versiones de los comparecientes. Una vez que se les haya corrido traslado de los informes recibidos, luego debe hacer una contrastación de la información en los términos del artículo 27B y, sí así lo desea, llamar a las partes a participar de una audiencia pública para decretar el reconocimiento de verdad y responsabilidad, según el artículo $27 \mathrm{C}$ de la citada Ley.

Por su parte, la Sección de Primera Instancia en casos de reconocimiento de verdad y responsabilidad, debe estudiar la resolución de conclusiones enviada por la Sala de Reconocimiento, evaluando la correspondencia "entre los hechos, las conductas reconocidas, las pruebas allegadas, las calificaciones realizadas, los responsables, la propuesta de la sanción, analizando las condiciones de contribución a la verdad y reparación en el marco del SIVJRNR", siguiendo lo establecido en el artículo 29 de la Ley 1922 de $2018^{12}$. Una vez establecida la correspondencia, la Sección deberá llamar a una audiencia de verificación (artículo 30 de la Ley 1922 de 2018) "a la cual se deberá convocar a los sujetos procesales y los intervinientes, con el fin de verificar el cumplimiento de las condiciones de contribución a la verdad y a la forma de reparación en el marco del SIVJRNR" ${ }^{13}$. Posteriormente, según el artículo 33 de la citada ley, "la Sección de Primera Instancia para Casos de Reconocimiento de Verdad y Responsabilidad proferirá la respectiva sentencia dando a conocer la sanción, sus condiciones y modalidades". Esta Sección es la encargada de aplicar lo que se conoce como las sanciones propias.

Ahora bien, tal como lo establece el propio Acuerdo, la principal función de la Sección de primera instancia para casos de ausencia de reconocimiento de verdad y responsabilidad, es la de "someter a la persona a juicio contradictorio y en su caso sancionarla o absolverla. La Sección podrá acordar que el juicio contradictorio se efectué en Audiencia Publica en presencia de las organizaciones de víctimas" (Gobierno de Colombia FARC EP, 2016, p. 162). La Ley 1922 de 2018, en su Título II también contempla un procedimiento contradictorio, asimilable al establecido en la Ley 906 de 2000 en su artículo 44. En dicho artículo contempla la posibilidad de realizar una audiencia restaurativa en los casos de reconocimiento tardío de responsabilidad, siempre y cuando este reconocimiento se realice antes del juicio oral.

Antes de exponer el procedimiento ante la Sala de Amnistía o Indulto y la Sala de Definición de Situaciones Jurídicas es importante mencionar que la Ley 1820 de 2016 regula algunas etapas de estos procedimientos y, por tanto, dialoga de manera constante con lo establecido en la Ley 1922 de 2018.

La Sala de Amnistía o Indulto tiene como función principal analizar la posibilidad de conceder los mencionados beneficios a las personas que se enmarquen en el factor personal, consagrado en el artículo 22 de la

del Departamento de Nariño; Caso 003: Muertes ilegítimamente presentadas como bajas en combate por agentes del Estado; Caso 004: Situación territorial de la Región de Urabá; Caso 005: Situación territorial Norte del Cauca en los municipios de Santander de Quilichao, Suárez, Buenos Aires, Morales; Caso 006: Victimización de miembros de la Unión Patriótica (UP); Caso 007: Reclutamiento de niñas y niños en el conflicto armado.

${ }^{12} \mathrm{Si}$ no hay correspondencia, se debe seguir lo establecido en el artículo 31 de la Ley 1922 de 2018.

${ }^{13} \mathrm{Si}$ se establece que el reconocimiento es parcial, se procederá según lo establecido en el artículo 32 de la Ley 1922 de 2018 . 
Ley 1820 de $2016^{14}$. La Sala de Amnistía o Indulto, siguiendo lo establecido en el artículo 45 de la Ley 1922 de 2018 puede analizar concesiones de estos beneficios:

- "Por remisión del listado al que se refiere el artículo $\underline{79}$, literal 1, de la Ley Estatutaria de Administración de Justicia en la JEP o las recomendaciones de la Sala de reconocimiento de verdad y responsabilidad y determinación de hechos y conductas".

- "Por remisiones que hagan la Sala de definición de situaciones jurídicas, la Unidad de Investigación y Acusación (UIA), la Sección de Primera Instancia para Casos de Ausencia de Reconocimiento de Verdad y Responsabilidad, y la Sección de Revisión".

- "A solicitud de parte [donde se] debe dirigir la solicitud de amnistía e indulto a la autoridad judicial que esté conociendo del proceso penal, esta de forma inmediata dará traslado de la petición a la Sala para lo de su competencia, anexando copia del expediente de oficio".

Asimismo, siguiendo lo establecido en el artículo 46 de la Ley 1922 de 2018, la Sala deberá determinar la conexidad o no, de las conductas objeto de posible concesión de amnistía o indulto, con el conflicto armado (primer nivel de análisis). Este proceso consiste en "un juicio valorativo acerca del nexo existente entre la conducta endilgada al compareciente y el desarrollo del conflicto armado. En este sentido, deberá establecerse si la conducta se cometió por causa, con ocasión, o en relación directa o indirecta con el conflicto armado" ${ }^{15}$. Respecto del delito político (segundo nivel de análisis), atendiendo a los criterios de conexidad (incluyente y excluyente) deberá establecer si se trata de conductas delictivas por las que no se concede la amnistía establecidos en el artículo 23 de la Ley 1820 de 2016. Para ello, la Sala podrá practicar distintas pruebas que lleven al esclarecimiento de los hechos y tipo penal (artículo 46 numeral 2 de la Ley 1922 de 2018). Una vez la Sala considere que cuenta con toda la información para poder pronunciarse de fondo, procederá a cerrar el trámite, siguiendo lo establecido en el artículo 46 de la Ley 1922 de 2018. La decisión, según el citado artículo, podrá tomarse en audiencia pública.

Algunos de los criterios excluyentes referidos, es decir los delitos por los que en ningún caso podrá concederse la amnistía son los constitutivos de lesa humanidad, el genocidio, los crímenes de guerra, la toma de rehenes u otra privación grave de la libertad, la tortura, las ejecuciones extrajudiciales, la desaparición for-

\footnotetext{
${ }^{14}$ La amnistía que se concede por la Sala de Amnistía e Indulto se aplicará a partir del día de entrada en vigor de esta ley, siempre y cuando los delitos hubieran sido cometidos antes de la entrada en vigor del Acuerdo Final de Paz, así como respecto a las conductas amnistiables estrechamente vinculadas al proceso de dejación de armas. Se aplicará a las siguientes personas, tanto nacionales colombianas como extranjeras que, en grado de tentativa o consumación, sean autores o partícipes de los delitos conexos al político conforme a lo establecido en el artículo siguiente respecto a criterios de conexidad, siempre que se de alguno de los siguientes requisitos:1. Que la providencia judicial condene, procese o investigue por pertenencia o colaboración con las FARC-EP, o 2. Integrantes de las FARC-EP tras la entrada en vigencia del Acuerdo Final de Paz con el Gobierno nacional, de conformidad con los listados entregados por representantes designados por dicha organización expresamente para ese fin, listados que serán verificados conforme a lo establecido en el Acuerdo Final de Paz. Lo anterior aplica aunque la providencia judicial no condene, procese o investigue por pertenencia a las FARC-EP, o 3. Que la sentencia condenatoria indique la pertenencia del condenado a las FARC-EP, aunque no se condene por un delito político, siempre que el delito por el que haya resultado condenado cumpla los requisitos de conexidad establecidos en esta ley, o 4. Quienes sean o hayan sido investigados, procesados o condenados por delitos políticos y conexos, cuando se pueda deducir de las investigaciones judiciales, fiscales y disciplinarias, providencias judiciales o por otras evidencias que fueron investigados o procesados por su presunta pertenencia o colaboración a las FARC-EP. En este supuesto el interesado, a partir del día siguiente de la entrada en vigor de esta ley, solicitará al Fiscal o Juez de Ejecución de Penas competente, la aplicación de la misma aportando o designando las providencias o evidencias que acrediten lo anterior.

15 Jurisdicción Especial para la Paz. Sala de Amnistía o Indulto. Resoluciones SAI-AOI-001-2018; SAI-AOI-002-2018; SAI-AOI003-2018; SAI - AOI-006-2019.
} 
zada, el acceso carnal violento y otras formas de violencia sexual, la sustracción de menores, el desplazamiento forzado, además del reclutamiento de menores, de conformidad con lo establecido en el Estatuto de Roma y los delitos comunes que carezcan de relación con la rebelión ${ }^{16}$.

Por su parte, la Sala de Definición de Situaciones Jurídicas es la encargada de definir la situación jurídica de las personas que no serán objeto de amnistía o indulto, bien porque la Sala de Amnistía o Indulto haya concluido que no lo son o por no enmarcar en el ámbito de competencia personal de la mencionada Sala. Esto último, podría referir a aquellos miembros de la fuerza pública que son parte de las Fuerzas Armadas, terceros que se hayan sometido voluntariamente, aquellas personas que no son incluidas en la resolución de conclusiones realizada por la Sala de Reconocimiento, o a las personas a las que no hay que exigírseles responsabilidad ante el Tribunal ya que han sido merecedoras de amnistías o indultos con anterioridad (Gobierno de Colombia - FARC EP, 2016, p. 296) . El ámbito de aplicación personal de esta Sala se encuentra definido en el artículo 29 de la Ley 1820 de $2016^{17}$. De igual manera, la Sala puede definir la situación jurídica de aquellas personas de la siguiente manera: "renuncia a la persecución penal; Cesación de procedimiento; Suspensión de la ejecución de la pena; Extinción de responsabilidad por cumplimiento de la sanción; Las demás resoluciones necesarias para definir la situación jurídica" ${ }^{18}$. En aras de definir la situación jurídica de las personas mencionadas, la Sala debe establecer si las conductas, objeto de análisis, se cometieron en el contexto y en razón del conflicto armado, y que no confluyan las excepciones contempladas en el artículo 30 de la Ley 1820 de $2016^{19}$.

\footnotetext{
${ }^{16}$ La Ley 180 de 2016 consagra en el parágrafo del artículo 23 los delitos que están excluidos de amnistía e indulto.
}

${ }^{17}$ Sin perjuicio de lo que se establece para los agentes del Estado en el Título IV de esta ley y de lo previsto en el Acuerdo de Jurisdicción Especial para la Paz, la Sala de Definición de Situaciones Jurídicas conocerá de los casos objeto de su competencia, respecto de las siguientes personas nacionales colombianos o extranjeros, bien sea que su responsabilidad sea a título de autoría o participación, consumación o tentativa: 1. Integrantes de las FARCEP tras la entrada en vigencia del Acuerdo Final de Paz con el Gobierno nacional, de conformidad con los listados entregados por representantes designados por dicha organización expresamente para ese fin, listados que serán verificados conforme a lo establecido en el Acuerdo Final de Paz. 2. Personas que, por conductas desplegadas en contextos relacionados con el ejercicio del derecho a la protesta o disturbios internos, hayan sido perseguidas penalmente, por los delitos contemplados en los artículos 112 (lesiones personales con incapacidad menor a 30 días), 265 (daño en bien ajeno), 353 (perturbación en servicio de transporte público, colectivo u oficial), 353A (obstrucción a vías públicas que afecte el orden público), 356A (disparo de arma de fuego), 359 (empleo o lanzamiento de sustancias u objetos peligrosos), $\underline{429}$ (violencia contra servidor público), 430 (perturbación de actos oficiales) y $\underline{469}$ (asonada) del Código Penal colombiano. Otras personas condenadas por delitos diferentes a los anteriores como consecuencia de participación en actividades de protesta podrán solicitar a la Sala de Definición de Situaciones Jurídicas el ejercicio de sus competencias respecto a sus condenas, si pudieran acreditar que las conductas por las que fueron condenados no son de mayor gravedad que las establecidas en los anteriores artículos del Código Penal. 3. Personas que estén procesadas o que hayan sido condenadas por delitos políticos o conexos vinculados a la pertenencia o colaboración con las FARC-EP, sin que se reconozcan parte de la anterior organización. En este supuesto la persona aportará las providencias judiciales u otros documentos de los que se pueda inferir que el procesamiento o la condena obedeció a una presunta vinculación con dicha organización. Lo anterior no obsta para que la Sala de Definición de Situaciones Jurídicas ejerza su competencia respecto a las personas indicadas en el parágrafo 63 del Acuerdo de Jurisdicción Especial para la Paz, en los términos previstos en dicho acuerdo.

${ }^{18}$ Ver también los artículos 49, 50 y 51 de la Ley 1922 de 2018.

${ }^{19}$ El artículo 30 de la Ley 1820 de 2016 consagra: “Criterios de valoración de la Sala de Definición de Situaciones Jurídicas. Podrán ser objeto de las resoluciones mencionadas en este capítulo las personas a quienes se les atribuyan los delitos que hayan sido cometidos en el contexto y en razón del conflicto armado, siempre que no constituyan:1. Casos de participación determinante en los denominados crímenes: crímenes de lesa humanidad, genocidio, graves crímenes de guerra, toma de rehenes u otra privación grave de la libertad, tortura, ejecuciones extrajudiciales, desaparición forzada, acceso carnal violento y otras formas de violencia sexual, sustracción de menores, desplazamiento forzado, o reclutamiento · de menores conforme a lo establecido en el Estatuto de Roma, sin perjuicio de la facultad contemplada en el numeral 2 del artículo 28 de esta ley. 2 . Delitos comunes que no hayan sido cometidos en el contexto y en relación con el conflicto armado o cuya motivación haya sido obtener beneficio personal, propio o de un tercero." 
Respecto a la Sección de Revisión es importante mencionar que tiene diferentes funciones, como, por ejemplo conocer de las acciones de tutelas en contra de providencias proferidas por la JEP. Entre los trámites que se pueden surtir ante esta sección está: el trámite de sustitución de la sanción penal iniciado por la Sala de Definición de Situaciones Jurídicas (artículo 52 de la Ley 1922 de 2018); el trámite de revisión de sentencias, proferidas por la justicia ordinaria, a solicitud de parte (Artículo 52A); el trámite referente a la aplicación, o no, de la garantía de no extradición consagrada en el artículo 19 transitorio del Acto Legislativo 1/2017 (artículo 54); expedir conceptos sobre la posible conexidad con la rebelión de las conductas de financiación a petición de las otras Salas y Secciones (artículo 55); resolver los conflictos de competencia entre las diferentes Salas y Secciones de la JEP (artículo 57), entre otros, contemplados en la citada Ley.

Por último, la Sección de Apelación, como órgano de cierre, tiene la función de conocer y de pronunciarse sobre todos los recursos de apelación que se interpongan en contra de las resoluciones y sentencias proferidas por las Salas y las Secciones de la JEP, en los términos de los artículos 13 y 59 de la Ley 1922 de 2018.

\section{Avances y retos: el funcionamiento de la JEP a través de algunos casos}

Es importante mencionar que la JEP empezó a operar el 1 de marzo del 2018. Durante estos dos años y medio de funcionamiento la Jurisdicción ha emitido diferentes resoluciones y sentencias que se enmarcan en algunos de los procesos anteriormente descritos. Por lo anterior, se hará una breve exposición de algunas decisiones que se han emitido a lo largo de estos años, para ejemplificar el funcionamiento de la Jurisdicción Especial para la Paz. Los casos que se expondrán en este capítulo se eligieron porque cada uno de ellos pone de manifiesto un reto que debió asumir la Jurisdicción en su momento ${ }^{20}$.

a. Caso 001 - Sala de Reconocimiento de Verdad, de Responsabilidad y de Hechos y Conductas

El caso 001 relativo a la "Retención ilegal de personas por parte de las FARC - EP"; abierto el 4 de julio de 2018 por parte de la Sala de Reconocimiento de Verdad, de Responsabilidad y de Hechos y Conductas a través del Auto 002 de 2018, responde a la estrategia de selección y priorización de las investigaciones que se llevan a cabo en el modelo de justica transicional que sienta las bases de la JEP (JEP, criterios y metodología de priorización de casos y situaciones, 2018).

Es importante recordar en este punto que esta estrategia de investigación responde sobre todo a la imposibilidad propia del organismo de procesar la universalidad de casos y situaciones que llegan ante los despachos judiciales (Díaz, 2012, p. 527). Si bien, esto resulta ser bastante controvertido, la realidad muestra que "los organismos estatales que administran justicia son incapaces de investigar, juzgar y sancionar todos los casos que llegan al sistema" (Díaz, 2012, p. 258). Es importante resaltar que tal como dice Binder, el sistema judicial debe responder a ciertas líneas procesales que le permitan a este orientar la selectividad de los casos o situaciones, conforme a ciertos valores, lo que permitirá maximizar su capacidad operacional (Binder, 2006, p. 213). Así, el proceso de priorización y selección por parte de la Sala se define "en términos de parámetros personales, asociando a individuos y a grupos de individuos la responsabilidad por los planes, políticas y patrones de macro-criminalidad competencia de la SRVR" (JEP, criterios y metodología de priorización de casos y situaciones, 2018, p. 3).

\footnotetext{
${ }^{20}$ Para este análisis, se recurrió al trabajo de ObservaJEP, un observatorio jurídico colombiano integrado por la Universidad del Rosario y la Universidad de la Sabana, que monitorea desde una aproximación jurídica el cumplimiento de los acuerdos y el funcionamiento óptimo de la JEP, el cual muestra importantes resultados y avances del trabajo que realiza la JEP. www.observajep.com
} 
Ahora bien, este caso ha sido construido con base en los informes aportados por la Fiscalía General de la Nación tales como el "Inventario de casos relacionados con el conflicto armado" y "Retenciones ilegales realizadas por parte de las FARC-EP"21 y los procesos que se surtieron, o están surtiendo, en la justicia ordinaria. A través de este caso, se prioriza el secuestro de personas efectuado por parte del grupo guerrillero de las FARC- EP entre los años 1993 y 2012, y se están investigado más de 9 mil hechos ocurridos durante esos años (JEP, Auto SRVR-002 del 4 julio de 2018).

Hasta la fecha, la JEP ha iniciado el trámite de siete casos y se espera que próximamente, el caso 001 sea el primero en donde la Sala de Reconocimiento de Verdad, de Responsabilidad y de Hechos y Conductas dicté la resolución de conclusiones. En ella se determinará si los comparecientes aportaron a la verdad y a la reparación de las víctimas, para posteriormente se pueda determinar las sanciones a cargo del Tribunal para la Paz. Se debe resaltar que en el marco del caso 001, la JEP ya (I) ha estudiado un Informe sobre el "Inventario del conflicto armado interno"; (II) ha analizado al menos 312 sentencias por hechos relacionados con secuestro en donde al menos 68 sentencias involucran miembros del Estado Mayor y del Secretariado de las FARCEP; también (III) ha analizado 42 expedientes judiciales que contienen hechos relacionados con la conducta de secuestro. A su vez, (IV) ha estudiado una base de datos aportada por "la Fundación País Libre sobre personas retenidas presuntamente por las FARC - EP, cuyo paradero se desconoce" y (V) por último, ha analizado dos informes entregados por el Centro de Memoria Histórica denominados "Una sociedad secuestrada" y "Guerrilla y población civil" (ObservaJEP, macro caso 001, 2019).

De igual manera, la Sala ha escuchado las versiones, en diversas ocasiones, de los antiguos dirigentes de las FARC-EP, en el marco de audiencias de reconocimiento. Hasta el 2019, y con base en el informe entregado por la JEP, se han proferido 16.500 decisiones judiciales, realizado 83 audiencias y a diciembre de 2019 , se habían recibido 256 versiones presenciales y 43 versiones escritas de comparecientes y se habían rendido seis versiones colectivas donde participaron 350 comparecientes ex integrantes de las FARC (JEP, comunicado 003, 2020), todos ellos relevantes al caso 001.

Por último, es de resaltar que en el marco del caso 0001, la Sala de Reconocimiento de Verdad, de Responsabilidad y de Hechos y Conductas ya ha acreditado alrededor de 2.107 víctimas, de las cuales 700 han presentado observaciones. Estas observaciones, "así como las versiones de los comparecientes, son sobre hechos y conductas que fueron tipificados en la justicia ordinaria como: secuestro simple, secuestro extorsivo, toma de rehenes, desaparición forzada y homicidio, entre otros tipos penales"(JEP, Caso 01: «Retención ilegal de personas por parte de las Farc-EP», 2020).

\section{b. Garantía de no extradición - Sección de Revisión}

Desde las negociaciones en La Habana se acordó la no extradición para miembros de las FARC-EP (Biblioteca del proceso de Paz, Tomo V, p. 550) con la finalidad de asegurar el reconocimiento pleno de la verdad por parte de los actores del conflicto y la eventual reparación de las víctimas (Gobierno de Colombia - FARC EP, 2016, p. 170). Dicho acuerdo se tradujo en la denominada garantía de no extradición. Como su nombre

\footnotetext{
${ }^{21}$ Frente al caso 001, la JEP ha dicho que: "Este caso prioriza el secuestro de personas por parte de las Farc-EP entre 1993 y 2012 e investiga más de 9 mil hechos ocurridos durante esos 19 años. Este periodo puede ser ampliado por la Sala de Reconocimiento de Verdad, de Responsabilidad y de Determinación de los Hechos y Conductas de la Jurisdicción. Dentro de esta primera etapa la Sala ha encontrado que las víctimas pueden llegar a ser más de 20 mil. La apertura de este caso se dio a partir de los informes que entregó la Fiscalía General de la Nación, Inventario de casos relacionados con el conflicto armado y "Retenciones ilegales realizadas por parte de las FARC-EP". En su desarrollo, el caso 01 se ha complementado con los informes de organizaciones como País Libre, la Asociación Colombiana de Víctimas de Desaparición Forzada y Otros Hechos Victimizantes (Acomides), y de otras agrupaciones de víctimas que fueron secuestradas por las Farc-EP, así como informes de la Fiscalía General de la Nación y del Centro Nacional de Memoria Histórica. También el caso 01 se ha complementado con los informes de Fevcol y de Fundegán, y de la Corporación Vivamos Humanos. En el caso 01 se utiliza el término con el cual la Fiscalía designó su informe No.2: "Retención ilegal de personas por parte de las FARC-EP". Con ello la JEP busca evitar acusaciones de prejuzgamiento al calificar jurídicamente la conducta antes del momento indicado por la ley.”. Encontrado en: https://www.jep.gov.co/Especiales/casos/01.html
} 
lo indica es "una garantía constitucional, que busca asegurar la consecución de la paz, garantizar la seguridad jurídica y los derechos de las víctimas a la verdad, la justicia y la reparación"(ObservaJEP, 2019). Se encuentra consagrada en el artículo 19 del acto Legislativo 1 de 2017, en los siguientes términos:

No se podrán conceder la extradición ni tomar medidas de aseguramiento con fines de extradición respecto de hechos o conductas objeto de este Sistema y en particular de la Jurisdicción Especial para la Paz, ocasionados u ocurridos durante el conflicto armado interno o con ocasión de este hasta la finalización del mismo, trátese de delitos amnistiables o de delitos no amnistiables, y en especial por ningún delito político, de rebelión o conexo con los anteriores, ya hubieran sido cometidos dentro o fuera de Colombia. Dicha garantía de no extradición alcanza a todos los integrantes de las FARC-EP y a personas acusadas de formar parte de dicha organización, por cualquier conducta realizada con anterioridad a la firma del acuerdo final, para aquellas personas que se sometan al SIVJRNR.

Asimismo, según lo contemplado en el artículo 54 de la Ley 1922 de 2018, la Sección de Revisión de la Jurisdicción Especial para la Paz es la responsable de conocer el trámite para la concesión de dicha garantía. A juicio de la Corte Constitucional colombiana (Sentencia C 112 del 13 de marzo de 2019), esta garantía constituye un cambio en el procedimiento ordinario de la figura de la extradición en Colombia, por lo que es importante que el ordenamiento jurídico interno se adapte a las nuevas realidades transicionales que responden a una concepción pro - paz (Organización de Naciones Unidas, artículo 1, 1945).

Uno de los casos más emblemáticos en donde la JEP ha sentado jurisprudencia en la materia fue en el caso de Seuxis Paucias Hernández Solarte, conocido como alias "Jesus Santrich", quien era miembro del Secretariado y excomandante de las FARC. Hernández fue solicitado por el Gobierno de los Estados Unidos el día 7 de junio de 2018 por la presunta comisión de delitos relacionados con el tráfico de estupefacientes hacia Estados Unidos. Este trámite, por competencia legal y siguiendo lo establecido en el artículo 19 del Acto Legislativo 1 de 2017, le correspondió resolverlo a la Sección de Revisión de la JEP. Toda vez que el señor Hernández Solarte se encontraba bajo la competencia de la JEP, la Sección de Revisión decidió concederle la garantía de no extradición al compareciente Jesús Santrich, por haber encontrado que no era posible determinar la fecha exacta de ocurrencia de los delitos alegados. A través del Auto SRT - AE - 030/2019, la Sección de Revisión estableció que dentro el trámite de la concesión o negación de la garantía de no extradición existen tres supuestos que se deben evaluar:

\begin{abstract}
"Primer supuesto. Para personas frente a quienes la solicitud de extradición relaciona que los hechos se cometieron antes de la firma del Acuerdo: en este supuesto se deben analizar dos factores: i) el personal -que el solicitante de la garantía haya sido integrante de las FARCEP-y ii) el material -que la conducta haya ocurrido durante el conflicto armado o con ocasión a este-.
\end{abstract}

Segundo supuesto. Cuando se alegue que los hechos ocurrieron con posterioridad a la firma del Acuerdo Final o del proceso de dejación de armas: si se da este supuesto, la prueba estará orientada a determinar la fecha de la ocurrencia del hecho, y así establecer si se dio con anterioridad o posterioridad a la firma del Acuerdo Final.

Tercer supuesto. Solicitud de extradición contra familiares de miembros de las FARC-EP: la garantía aplica para familiares hasta el segundo grado de consanguinidad o primero de afinidad. En este caso la Sección deberá estudiar si la conducta ocurrió antes de la suscripción del Acuerdo Final, y si guarda relación con la pertenencia del familiar a las FARC-EP” (ObservaJEP, Ficha técnica Jesús Satrich 2019, pp. 5-6). (Negrilla y subrayado por fuera de texto).

En la sentencia también se destacó que la Sección era competente para analizar tres elementos sobre la solicitud de garantía de no extradición: el elemento fáctico, probatorio y jurídico. A su vez, se determinó los principios de interpretación que deben guiar el análisis de la concesión o no de esta garantía constitucional tales como: (I) el principio de la no extradición como garantía cuya titularidad ya recae en los ex combatientes 
de las FARC, en donde la Sección hizo referencia al Auto del 31 de octubre de 2018, de la Corte Suprema de Justicia de Colombia el cual estableció que los ex combatientes de las FARC - EP se encuentran amparados por esta garantía; (II) el principio pro homine, que establece el deber del operador jurídico de adoptar la interpretación menos restrictiva de un derecho que pueda haber; (III) el principio pro víctima, en virtud del cual se entiende que la garantía de no extradición colabora con la materialización de los principios rectores del SIVNJRN, ya que facilita la comparecencia presencial de los implicados, el reconocimiento de responsabilidad y la contribución a la verdad por parte de los comparecientes ex integrantes de las FARC - EP; y finalmente (IV) el principio pro paz, el cual orienta a que las decisiones adoptadas constituyan un paradigma que oriente en materia normativa y jurisprudencial la interpretación de normas y procedimientos que sean inherentes a la transición en Colombia (Sección de Revisión, Tribunal para la Paz, SRT-AE-030, 2019).

Respecto al factor de competencia personal, la Sección de estableció que la garantía de no extradición puede ser aplicada en favor de (i) integrantes de las FARC-EP, (ii) personas acusadas de ser integrantes de las FARC-EP, y (iii) familiares hasta el segundo grado de consanguinidad o primero de afinidad de integrantes de las FARC-EP o de personas acusadas de ser integrantes de la mencionada organización. No obstante, precisó que cuando se trate de un miembro de la fuerza pública o de un tercero, esta garantía no los cobija, toda vez que "(i) el artículo transitorio 19 establece de manera taxativa los beneficiarios de la garantía de no extradición; (ii) bajo ninguna circunstancia, una persona que no se encuentre en las tres categorías anteriormente indicadas podrá acceder a la garantía de no extradición, y (iii) en consecuencia, un tercero colaborador o un miembro de la fuerza pública no podrán ser titulares del dicho beneficio"(ObservaJEP, La JEP en observación: Análisis jurisprudenciales y retos vigentes, 2020, p. 18).

Si bien el caso que se mencionó no ha sido el único sobre el trámite de la garantía de no extradición ante la Sección de Revisión, si es una providencia judicial que marca una pauta para los futuros casos en donde se deba conceder o no esta garantía para los comparecientes sometidos a la competencia de la JEP.

c. Caso de la Sección de Apelación: ¿pueden los paramilitares comparecer ante la JEP?

La Sección de Apelación, al ser el órgano de cierre del Tribunal para la Paz, está llamado a unificar la jurisprudencia en materia de justicia transicional. En ese sentido, es importante traer a colación el Auto 199 de 2019 pues este se considera como una providencia hito referente a la competencia de la JEP con respecto a miembros de los grupos paramilitares. En principio, los integrantes de grupos paramilitares no son competencia de la JEP pues como bien lo explica ObservaJEP en su informe "La JEP en observación: análisis jurisprudenciales y retos vigentes" (2020), existen diversas razones para ello:

a. El Acuerdo Final no contempló en el Punto 5 la inclusión de paramilitares a la jurisdicción de la JEP.

b. El marco normativo (actos legislativos, ley estatutaria, ley de procedimiento, ley de amnistía, etc.) de la JEP carece de normas expresas que otorguen la competencia a la jurisdicción sobre paramilitares.

c. La competencia de la JEP versa sobre grupos armados organizados (GAO's) de naturaleza rebelde.

d. Tanto en el Acuerdo Final como en la normativa de la JEP se establece con claridad que la competencia de esta jurisdicción versa sobre grupos que hayan celebrado un acuerdo de paz con el Estado. Los paramilitares no han celebrado dicho acuerdo ya que se entiende que el Pacto de San José de Ralito fue un acuerdo de desmovilización.

e. Los paramilitares no pueden acogerse como terceros civiles ya que su naturaleza es decisivamente excluyente con esta categoría.

f. Los paramilitares cuentan con un régimen jurídico propio enmarcado en la ley 975 de 2005 (p. 38)

Estas razones, responden propiamente a la concepción misma de los Acuerdos de Paz así como también a la esencia del SIVJNR, en donde los paramilitares no son sujetos susceptibles del proceso de Justicia Transicional. No obstante, la Sección de Apelación ha flexibilizado, de cierto modo, la competencia personal con 
respecto a integrantes de grupos paramilitares. Por medio del Auto 199 de 2019, la Sección determinó que, si bien la regla general era la de excluir a los paramilitares de la órbita de la competencia personal de la JEP, hay supuestos en que esta exclusión puede variar ya que el rol de paramilitar puede hacer transición o pudo haber mutado a lo largo del conflicto armado hacía un rol de tercero colaborador de grupos armados, como lo fueron las FARC-EP, caso en el cual, sí podrían ser competencia de la JEP (Sección de Apelación, 2019).

En esta misma providencia, la Sección de Apelación también aclaró que si bien la JEP no tiene competencia personal sobre estos sujetos, esto no significa que el juez que evalúe la comparecencia de uno de estos sujetos, no deba analizar el caso en particular, pues se pueden presentar situaciones en donde se justifique excepcionalmente, hacer una interpretación más amplia de las competencias de la JEP. Esto siempre que los eventos se interpreten en que el interés superior de las víctimas, en especial el de obtener la verdad, sea requerido. Del mismo modo, el auto reitera las exigencias de acreditar un test de verdad del que hablan los autos TP SA 57 y TP - SA 19 de 2018 y autos TP - SA 126 y 135 de 2019, pues este test permite "(I) romper con la presunción de que los paramilitares fueron solamente actores armados, pues para que puedan someterse a la JEP no importa el status que ostentaron como militantes; (II) asegurar que el tercero civil revele todo lo que conoce y (III) brindar información que resulte ser relevante a la JEP"'(ObservaJEP, Ficha técnica Auto TP SA 199, 2019, p. 6).

\section{d. Caso sobre el trámite de amnistía - Sala de Amnistía o Indulto}

Como se mencionó anteriormente, el artículo 21 de la Ley 1820 de 2016, dispone que "la decisión de conceder amnistías o indultos dependerá de la Sala de Amnistía e Indulto de la Jurisdicción Especial para la Paz". A su vez, afirma que se deberá "dar aplicación al principio de favorabilidad regulado en esta ley y de lo establecido en el artículo 6.5 del Protocolo Adicional 11 de las Convenciones de Ginebra de 1949, la Sala aplicará la amnistía o el indulto conforme a lo establecido en esta ley y en el Acuerdo de creación de la Jurisdicción Especial para la Paz". Esta misma ley, establece el régimen de amnistías e indultos tanto para miembros de las FARC - EP así como también para los civiles. Frente a los agentes estatales, la ley en comento estableció un régimen de renuncia a la persecución penal y de extinción de la acción penal, de la responsabilidad penal y de la sanción (CIJ, 2019, p. 97). En específico, frente a la amnistía, se debe resaltar que su concesión se encuentra legitimada desde el Derecho Internacional Humanitario (DIH), pues el Protocolo Adicional II a los Convenios de Ginebra de 1949 en el numeral 5 del artículo 6. Dicho artículo permite que instrumentos jurídicos que buscan la reconciliación entre los actores armados y la construcción de una paz estable y duradera, sean utilizados (Sala de Amnistía e Indulto, caso Fredy Molina, SAI-SUBA-AOI-005, 2019).

En Colombia, la amnistía juega un papel importante dentro del marco del proceso transicional y la Corte Constitucional ya ha determinado en su jurisprudencia que las amnistías resultan ser "medidas compatibles, con el DIH, específicamente, en los conflictos no internacionales, pues persiguen que las personas que participaron en la confrontación no sean castigadas por el solo hecho de portar las armas, lo que haría muy difícil el proceso de reconciliación" (Corte Constitucional, 2018). La concesión de amnistías por parte de la JEP para antiguos miembros de las FARC-EP está estructurada de la siguiente manera: (i) concesión de amnistías de iure para las conductas constitutivas de delitos políticos, (ii) exclusión de determinadas conductas del beneficio de amnistía (artículo 23 de la Ley 1820 de 2016) y (iii) concesión de amnistías por parte del Juez, en esta caso la Sala de Amnistía o Indulto, para cualquier delito que no se encuentre excluido, siempre que se pueda establecer la conexidad con el conflicto armado y con el delito político (Reyes Alvarado, p. 28).

Ahora bien, dentro de los casos más importantes donde se ha dado trámite a una amnistía por parte de la Sala de Amnistía e Indulto, se encuentra el caso de Fredy Hernán Molina Cruz. En este caso, con la Resolución SAI - SUBA-AOI-005 de 2019, la Sala resaltó que un compareciente puede ser beneficiario de esta figura siempre que cumpla con los factores de competencia personal, temporal y material de la JEP. En este sentido, frente al factor personal, la persona debe haber sido condenada, procesada o investigada por pertenencia $\mathrm{o}$ colaboración con las FARC - EP; o debió haber sido integrante de este grupo para lo cual debe encontrarse dentro de los listados entregados por los representantes designados por la organización; o debe haber una 
sentencia condenatoria que indique que esa persona pertenencia a las FARC - EP incluso sino se trata de un delito político, por lo que si se trató de otro delito, debe estar conexo con el delito político (ObservaJEP, Ficha técnica Resolución SAI-SUBA-AOI-005, 2019, p. 8).

Con respecto al factor temporal, los hechos materia de concesión de este beneficio debieron haberse cometido antes del 1 de diciembre de 2016; y frente al factor material, para que la amnistía sea concedida, se debe tratar de hechos relacionados con el conflicto armado, así como también tratarse de delitos políticos o conexos con este, es decir, donde el sujeto pasivo sea el Estado y cuando esa conducta antijuridica haya sido cometida sin ánimo de lucro personal (ObservaJEP, Ficha técnica Resolución SAI-SUBA-AOI-005, 2019, p. 10). Frente a estos delitos, el artículo 15 de la Ley 1820 establece que son la rebelión, la sedición, la asonada, la conspiración y seducción, y la usurpación y retención ilegal de mando.

En el caso de la resolución mencionada, el delito que se analizó fue el lavado de activos, por lo que la Sala tuvo que hacer un análisis más extenso para establecer la conexidad con el delito político. Dentro del análisis realizado por la Sala se determinó que a través de la "compra y administración de bienes muebles e inmuebles, la realización de transferencias financieras, entre otras actividades, se contribuyó a financiar el desarrollo de la rebelión, lo cual se traduce en que la conducta por la cual se condenó a los aquí comparecientes, sí tenga un nexo con el delito político" (ObservaJEP, Ficha técnica Resolución SAI-SUBA-AOI-005, 2019, p. 13). Finalmente, en el caso de Fredy Molina y los demás comparecientes que se mencionaban en la decisión, la Sala de Amnistía e Indulto determinó que dado que se cumplían los factores de competencia analizados y el rol por el cual podían estar en la JEP era el de colaboradores de grupos armados, era posible conceder el beneficio de la amnistía.

\section{e. Casos de incidentes de verificación de incumplimiento}

El incidente de verificación de incumplimiento es un procedimiento realizado por la JEP, cuyo objetivo es establecer si el compareciente continúa cumpliendo con los compromisos de su régimen de condicionalidad al estar sometido al SIVJNR. En caso de incumplimiento, la JEP deberá determinar si revoca o no los beneficios otorgados a ese compareciente o hasta llegar a expulsar a esta persona cuando se trate de un grave incumplimiento de los acuerdos a los cuales que se había comprometido (ObservaJEP, La JEP en observación: análisis jurisprudenciales y retos vigentes, 2020. p. 29). El trámite del incidente de incumplimiento se encuentra regulado en el artículo 67 de la Ley 1922 de 2018, que establece claramente que este puede ser iniciado por cualquier Sala o Sección de la JEP.

Frente a este procedimiento, la Corte Constitucional ha mencionado en Sentencia C- 007 (2018) que existen tres principios que la JEP debe tener en cuenta al momento de verificar el grado de incumplimiento del compareciente:

1. Principio de integralidad del sistema: todos los tratamientos especiales de justicia están sujetos a condiciones en relación con todos los componentes, judiciales y no judiciales, del SIVJRNR, los cuales no pueden entenderse de manera aislada, razón por la que el incumplimiento de condiciones respecto de cualquiera de tales componentes podría tener consecuencias en los tratamientos de justicia.

Principio de proporcionalidad: Las consecuencias del incumplimiento de las condiciones serán proporcionales a la gravedad del mismo, su naturaleza y el tratamiento otorgado.

3. Principio de gradualidad: no cualquier incumplimiento da lugar a la pérdida de todos los beneficios, sino que se deberán graduar sus consecuencias, distinguiendo los diferentes niveles de responsabilidad, la gravedad e intencionalidad del incumplimiento y la afectación de las finalidades del SIVJRNR. De esta manera, el incumplimiento del régimen de condicionalidad no conlleva a la exclusión de la JEP, sino que la jurisdicción graduará la pérdida de los diferentes tratamientos especiales, pues el incumplimiento de las condiciones no solo impide acceder a los tratamientos diferenciales, sino que también 
implica la pérdida, no de la competencia de la JEP, sino de los tratamientos especiales, con sujeción al principio de gradualidad (Corte Constitucional, Sentencia C-674 de 2017, página 367 , parr 5.5.1.1).

Hasta la fecha, la JEP ha abierto innumerables incidentes de verificación de incumplimiento, donde solo una minoría han establecido la expulsión definitiva del SIVJNR y en gran parte de los casos analizados, se ha determinado que los comparecientes deben perder algunos de los beneficios que otorgan los tratamientos especiales en el marco de la justicia transicional en Colombia.

En el último informe presentado por ObservaJEP a principios del 2020, se analizaron distintos casos de varios de los comparecientes o personas que son competencia de la JEP. De los siete casos que se analizaron en el informe, solamente dos de ellos muestran la expulsión de los comparecientes. Por ejemplo, en el caso del señor Hernán Darío Velásquez, que fue expulsado por medio de auto 061 de la mencionada Sala (2019) por "no concurrir a la diligencia del 13 de julio de 2018, sin presentar excusa; así como tampoco presentó el informe requerido sobre el cumplimiento de las obligaciones constitucionales y legales individuales con el SIVJRNR, donde tampoco excusó su falta" (ObservaJEP, La JEP en observación: análisis jurisprudenciales $y$ retos vigentes, 2020. p. 32).

Del mismo modo, en los casos de los comparecientes de los señores Iván Márquez, José Manuel Sierra y Henrry Castellanos, ellos fueron expulsados por faltar a la obligación de contar la verdad lo que es contrario al derecho a la reparación de las víctimas (ObservaJEP, La JEP en observación: análisis jurisprudenciales y retos vigentes, 2020. p. 32). También, por incumplir la obligación expresa de abandonar las armas, por repetir hechos delictivos e ilícitos y por entorpecer la contribución del éxito de la reincorporación, compromisos que adquirieron en el momento de la firma del Acuerdo. En el Auto 216 de la Sala de Reconocimiento de Verdad, Responsabilidad y de Determinación de los Hechos y Conductas (2019) se "decidió decretar la pérdida de todos los beneficios de la justicia transicional y por tanto la exclusión de la JEP, dado el grave incumplimiento en el que incurrieron estas personas" (ObservaJEP, La JEP en observación: análisis jurisprudenciales y retos vigentes, 2020. p. 32).

De esta forma, la máxima consecuencia que puede tener un compareciente que estuvo sometido a la JEP es la expulsión del SIVJRN. Como consecuencia, la jurisdicción penal ordinaria será la competente de investigar, juzgar y sancionar conforme el derecho correspondiente y sin acceso a los beneficios del proceso de Justicia Transicional. No obstante, casos como los de los señores Hernán Darío Velásquez, José Vicente Lesmes en los que no se ha determinado su expulsión, pero si en la perdida de los beneficios transicionales (como la perdida de libertades condicionadas o la perdida de los tratamientos penales especiales que se contemplan en el marco de la Ley 1820 de 2016), demuestra que el análisis de gravedad del incumplimiento que hace la JEP no siempre arroja como consecuencia una expulsión y, por tanto, esta no se constituye como la sanción general ante el incumplimiento de los compromisos por parte del compareciente. Por el contrario, la expulsión, al ser la consecuencia más grave, se aplica por un incumplimiento igualmente grave que ponga en peligro los derechos de las víctimas.

Los casos expuestos anteriormente dan cuenta solamente de una parte del universo de procesos y casos que se encuentran actualmente en trámite ante la JEP. Este órgano judicial, enmarcado dentro de la creación de un sistema novedoso y que responde a las necesidades de las víctimas, evidencia el trabajo que realiza la jurisdicción para satisfacer los derechos de las partes y lograr cumplir los objetivos propuestos en el Acuerdo final.

Así, el caso 001 implicó un ejercicio de priorización y selección de conductas por parte de la Sala de Reconocimiento que atendió al hecho de que el secuestro fue una forma clara de hacer la guerra por parte de las FARC-EP durante un largo periodo de tiempo. Esta conducta es característica del conflicto armado colombiano y, por lo mismo, es de suma importancia que, tanto las víctimas como la sociedad en general conozcan la verdad de lo sucedido para ser reparadas y que los actores sean sancionados. Asimismo, el caso 001 es uno 
de los que se encuentra más avanzados y ejemplifica el procedimiento de las Salas, que es central y fundamental para el funcionamiento de la JEP. Igualmente representa el núcleo de este modelo de Justicia Transicional porque dentro de este se busca satisfacer el derecho a la verdad y a la reparación de las víctimas.

Por su parte, el caso de la concesión de la garantía de no extradición al señor Hernández ejemplifica la labor de la Sección de Revisión relativa a establecer las fechas de determinadas conductas. Esta labor parece sencilla, pero como lo pone de manifiesto el caso analizado, no lo es. El caso de la Sección de Apelación muestra que es imposible encasillar a los actores del conflicto en un solo rol y, a través de la resolución de este, se dotó de contenido el concepto de "terceros colaboradores" tan etéreo y de difícil comprensión. De igual manera evidencia la complejidad del conflicto armado colombiano, en el que participaron muchos actores que cumplieron diferentes funciones durante el tiempo que este duró.

El caso de la Sala de Amnistía o Indulto muestra que, en ocasiones, establecer la conexidad con el delito político para la concesión de un beneficio transicional no es sencillo. Pero además pone de manifiesto que dentro del conflicto armado se realizaron conductas delictivas de todo tipo que no necesariamente concuerdan con las acciones de guerra que están en el imaginario colectivo pero que, no por eso, dejan de ser susceptibles de un beneficio transicional como lo es la amnistía. De igual modo, el caso es un claro ejemplo de la necesidad de amnistiar algunas conductas, en aras de alcanzar la paz y que ello no necesariamente implica impunidad.

Por último, el incidente de incumplimiento muestra que, en ocasiones, los comparecientes no cumplen con lo pactado y que es necesario que los sistemas transicionales contemplen sanciones para estos incumplimientos. Sumado a lo anterior, muestra que la expuslsión del sistema debe ser la última vía para castigar a quienes incumplen las obligaciones. Ello puede obedecer al hecho de que, al sacar a los comparecientes del sistema, la posibilidad de obtener la verdad completa se ve debilitada, así como la reparación integral para las víctimas.

\section{Conclusiones}

En las páginas precedentes se hizo una exposición de los objetivos, la estructura y el funcionamiento de la JEP que fue ejemplificado a través de algunos casos que ha conocido dicha jurisdicción. Con base en lo expuesto se puede concluir que la JEP es un modelo de justicia transicional que responde a las necesidades propias del conflicto aramdo colombiano, así como a las de la sociedad del postconflicto. De igual manera, a través de su estructura y organización, se evidencia la complejidad de este órgano judicial que refleja la complejidad misma de los procesos que se llevan ante ella. Ello se evidencia en los casos analizados, que no sólo son muestra de los distintos retos que asume la JEP en el cumplimiento de su trabajo, sino de las tensiones propias de un modelo de justicia transicional que se considera, en teoría, un híbrido entre la justicia restaurativa y la justicia retributiva. Si bien se está buscando el castigo de los responsables de los delitos cometidos con ocasión directa o indirecta al conflicto armado, también se busca resarcir a las víctimas en sus derechos, asegurándoles verdad, justicia, reparación y garantías de no repetición, así como también un proceso de integración social de aquellos comparecientes que después de la guerra, asumen roles dentro de una sociedad.

\section{Bibliografía}

Abuchaibe, H. (2017). La justicia transicional del posacuerdo con las FARC-EP. Revista Opera. vLex. http://doctrina.vlex.com.co/vid/justicia-transicional-posacuerdo-farc-844458857

Ávila, A. (2019). Detrás de la guerra en Colombia. 1. ed. Planeta.

Barbosa Delgado, F. (2018). Justicia: Balance de la contribución del CNMH al esclarecimiento histórico. Centro Nacional de Memoria Histórica. 
Benavides Vanegas, F. S., \& Borda Guzmán, S. (2019). Introducción: El Acuerdo de Paz entre el Gobierno colombiano y las FARC-EP o la paz esquiva. Introduction: The Peace Agreement between the Colombian government and the FARC-EP, or the elusive peace, 121, 7-18. https://doi.org/10.24241/rcai.2019.121.1.7

Biblioteca del proceso de paz con las FARC - EP (2018), Tomo V. Parte II. "La discusión del punto 5. Bogotá: Oficina del Alto Comisionado para la Paz, p 550. Recuperado el 01 de septiembre de 2020, de https://www.jep.gov.co/Sala-de-Prensa/Documents/tomo-5B-proceso-paz-farc-acuerdo-victi$\underline{\text { mas.pdf }}$

Binder, A. M. (Ed.). (2006). Derecho procesal penal (1. ed). Escuela Nacional de la Judicatura.

Calafat, A. L. (2016). La justicia transicional en Colombia / Transitional justice in Colombia. (En)clave Comahue, 21, 233-233-260. Directory of Open Access Journals.

Castro Cuenca, C. G. (2020). Las funciones del derecho penal y de la justicia transicional en la jurisdicción especial para la paz. Bogotá: Vniversitas, 69, 1-17. https://doi.org/10.11144/Javeriana.vj69.fdpi

Congreso dela República de Colombia (04 de abril de 2017), Acto Legislativo $\mathrm{N}^{\circ} 01$ " por medio del cual se crea un título de disposiciones transitorias de la constitución para la terminación del conflicto armado y la construcción de una paz estable y duradera y se dictan otras disposiciones". Recuperado 2 de julio de 2020, de https://dapre.presidencia.gov.co/normativa/normativa/ACTO\%20LEGISLATIVO\%20N\%C2\%B0\%2001\%20DE\%204\%20DE\%20ABRIL\%20DE\%202017.pdf

Congreso de la República de Colombia (18 de julio de 2018), Ley 1922 "Por medio de la cual se adoptan unas reglas de procedimiento para la Jurisdicción Especial para la Paz". (s. f.). Recuperado 6 de julio de 2020, de https://dapre.presidencia.gov.co/normativa/normativa/LEY\%201922\%20DEL\%2018\%20DE\%20JULIO\%20DE\%202018.pdf

Congreso de la República de Colombia, (30 de diciembre de 2016), Ley 1820 "Por medio de la cual se dictan disposiciones sobre amnistía, indulto y tratamientos penales especiales y otras disposiciones". Recuperado 11 de septiembre de 2020, de http://es.presidencia.gov.co/normativa/normativa/LEY\%201820\%20DEL\%2030\%20DE\%20DICIEMBRE\%20DE\%202016.pdf

Comisión Internacional de Juristas - CIJ (junio de 2019), Jurisdicción Especial para la Paz, análisis a un año y medio de su entrada en funcionamiento. (s. f.). Recuperado 11 de septiembre de 2020, de https:/www.icj.org/wp-content/uploads/2019/06/Colombia-Jurisd-para-la-paz-PUBLICATIONS-Reports-Fact-finding-mission-report-2019-SPA.pdf

Corte Constitucional (13 de marzo de 2009). Sentencia C - 112. Recuperado en: https://www.corteconstitucional.gov.co/relatoria/2019/C-112-19.htm

Corte Constitucional (1 de marzo de 2018). Sentencia C - 007. Recuperado de: https://www.corteconstitucional.gov.co/relatoria/2018/C-007-18.htm

Corte Constitucional (14 de noviembre de 2017), Sentencia - 674. Recuperado de: https://www.corteconstitucional.gov.co/relatoria/2017/C-674-17.htm

Díaz, C. L. (2012). Selección y priorización de delitos como estrategia de investigación en la justicia transicional. Revista FACULTAD DE DERECHO Y CIENCIAS POLÍTICAS, 42, 515-579.

El Tiempo, C. E. E. (marzo 03 de 2020). ¿Secuestro o retención?: Los polémicos términos del caso 01 de la JEP. El Tiempo. https://www.eltiempo.com/justicia/jep-colombia/secuestro-o-retencion-lospolemicos-terminos-de-la-jep-en-caso-468530 
Ferrajoli, L. (2015). La justicia penal transicional en la Colombia del posconflicto y las garantías de la paz interna. Jueces para la democracia, 84, 143-155.

Gobierno de Colombia \& FARC - EP (2016). Acuerdo final para la terminación del conflicto y la construcción de una paz estable y duradera.

De Grieff, P. (2011). Algunas reflexiones acerca del desarrollo de la Justicia Transicional. Anuario de Derechos Humanos, 0(7). https://doi.org/10.5354/0718-2279.2011.16994

Jurisdicción Especial para la Paz - JEP (2020), Caso 001: «Retención ilegal de personas por parte de las FarcEP». (s. f.). Recuperado 10 de septiembre de 2020, de https://www.jep.gov.co/Especiales/casos/01.html

Jurisdicción Especial para la Paz - JEP (28 de junio de 2018). Criterios y Metodología de priorización de casos y situaciones. Bogotá. Recuperado el 01 de septiembre de 2020 en: https://www.jep.gov.co/Documents/CriteriosYMetodologiaDePriorizacion.pdf

Jurisdicción Especial para la Paz - JEP (enero de 2020). Comunicado 003 "La JEP presentó el balance de su segundo año de gestión". Bogotá. Sala de Prensa. Recuperado el 03 de septiembre de 2020 en: https://www.jep.gov.co/Sala-de-Prensa/Paginas/La-JEP-present\%C3\%B3-balance-de-su-segundo-a $\%$ C3\%B1o-de-gesti\%C3\%B3n.aspx

López, C. (2010). Y refundaron la patria. De cómo mafiosos y políticos reconfiguraron el Estado colombiano. Editorial Randon House Mondadori.

Mendaña, R. (2007). Ejercicio de la acción penal y principio de oportunidad. Recuperado de http://new.pensamientopenal.com.ar/sites/default/files/2012/02/microsoft_word_- 44men_0.pdf.

ObservaJEP (2020). Macrocasos: Caso 001. Recuperado 10 de septiembre de 2020, de http://observajep.com/images/macrocasos/1.pdf

ObservaJEP (2019. Ficha técnica Auto TP - SA 199 DE 2019. (s. f.). Recuperado 11 de septiembre de 2020, de http://observajep.com/images/fichas_tecnicas_decisiones/18349584125d49e8af63cc35.92615999.pdf

ObservaJEP (2019), Ficha técnica Resolución SAI-SUBA-AOI-005-2019. (s. f.). Recuperado 11 de septiembre de 2020, de http://observajep.com/images/fichas_tecnicas_decisiones/2239086695db06f5e766435.06579227.pdf

ObservaJEP (enero de 2020), La JEP en observación: Análisis jurisprudenciales y retos vigentes. (s. f.). Recuperado 11 de septiembre de 2020, de http://observajep.com/images/informes/3882996405e5551de42af47.98545643..pdf

ObservaJEP. (2019). Ficha técnica caso de Seuxis Paucias Hernandez Solarte. Recuperado 11 de sptiembre de 2020, de http://observajep.com/images/fichas_tecnicas_decisiones/9427195255d3595d8a1c542.34540100.pdf.

Organización de Naciones Unidas - ONU (26 de junio de 1945), Carta de las Naciones Unidas. Recuperado de: https://www.oas.org/36ag/espanol/doc_referencia/Carta_NU.pdf

Pizarro, E. (2017). Cambiar el futuro. Historia de los procesos de paz en Colombia (1981 - 2016). Bogotá: Debate.

Reyes Alvarado, Y., Eser, A., Knust, N., \& Neumann, U. (Eds.). (2018) ¿Es injusta la justicia transicional? (Primera edición). Universidad Externado de Colombia, Centro de Investigación en Filosofía y Derecho. 
Sala de Amnistía e indulto - JEP (20 de febrero de 2019), Resolución SAI-SUBA-AOI-005 en el asunto sobre concesión de amnistía de Fredy Molina. Recuperado el 10 de septiembre de 2020 de: https://bit.ly/2ozEjNq

Sección de Apelación - Tribunal para la Paz (11 de junio de 2019), Auto 199 sobre el caso de Fabio Cesar Mejía Correa. Recuperado el 10 de septiembre de 2020 de: https://bit.ly/2K5Rqhj

Sección de Apelación - Tribunal para la Paz (20 de abril de 2018) Auto TPSA- 001 de 2018.

Sección de Apelación - Tribunal para la Paz (31 de octubre de 2018), Auto TP - SA $n^{\circ} 57$ en el asunto de Duvan Hurtado Henao. Recuperado el 11 de septiembre de 2020 en https://relatoria.jep.gov.co/documentos/providencias/7/1/Auto_TP-SA-057_31-octubre-2018.pdf

Sección de Apelación - Tribunal para la Paz (21 de agosto de 2018), Auto TP - SA $n^{\circ} 79$ en el asunto de Álvaro Antonio Ashton Giraldo. Recuperado el 11 de septiembre de 2020 en: https://www.jep.gov.co/Sala-de-Prensa/Documents/Auto\%20TP-

SA $\% 20020 \% 20 \mathrm{de} \% 202018 \% 20-\% 20 \mathrm{En} \% 20 \mathrm{el} \% 20$ asunto $\% 20 \mathrm{de} \% 20 \% \mathrm{C} 3 \% 81$ lvaro\%20Ashton $\% 20-\% 20$ DEF.pdf

Sección de Apelación - Tribunal para la Paz (27 de marzo de 2019), Auto TP - SA N ${ }^{\circ} .135$ en el asunto de Dorian Jaime Mejía Geleano. Recuperado el 10 de septiembre de 2020 de: https://relatoria.jep.gov.co/documentos/providencias/7/1/Auto_TP-SA-135_27-marzo-2019.pdf

Sección de Revisión - Tribunal para la Paz (15 de mayo de 2019), Auto SRT-AE-030 en el caso de Seuxis Paucias Hernández S. Recuperado el 11 de septiembre de 2020 de: https://www.jep.gov.co/Sala-de-Prensa/SiteAssets/Paginas/LA-SECCI\%C3\%93N-DE-REVISI\%C3\%93N-DE-LA-JEP-APLICA-LA-GARANT\%C3\%8DA-DE-NO-EXTRADICI\%C3\%93N-A-SEUXIS-PAUCIAS-HERN\%C3\%81NDEZ-SOLARTE/SRT-AE-0302019.pdf

Teitel, R. G. (2000). Transitional justice. Oxford University Press.

Uprimny, R. (2006). Las enseñanzas del análisis comparado: Procesos transicionales, formas de justicia transicional y el caso colombiano. ¿Justicia transicional sin transición?, 115.

Valencia, L. (2008). Parapolítica: la ruta de la expansión paramilitar y los acuerdos políticos. Planeta/Nuevo Arco Irís.

Villarraga- Sarmiento. A. (2016). Los acuerdos de paz Estado-guerrillas en Colombia, 1982-2016. Derecho y Realidad, 14(28). https://doi.org/10.19053/16923936.v14.n28.2016.7815 